\title{
Modeling environmental impact of service sectors to promote sustainable development of Thailand
}

\author{
Pruethsan Sutthichaimethee*, Yothin Sawangdee
}

Institute for Population and Social Research, Mahidol University, Nakhonpathom 73170, Thailand

\begin{abstract}
The objective of this research is to propose an indicator to assess and rank environmental problems caused by production within the services sector of Thailand. Factors used to calculate real benefit (defined as revenue for a sector, minus the environmental costs) included the costs of (1) natural resources materials, (2) energy and transportation, (3) fertilizer and pesticides, and (4) sanitary and similar services. The highest environmental cost in terms of natural resources materials and energy and transportation was in the service sector - hotels and places of lodging, while the highest environmental cost in terms of fertilizer and pesticides was in the service sector - personal services. The service sector - movie theaters had the highest environmental cost for sanitary and similar services. Overall, the service sector - real estate gained the highest real benefit, while the service sector - repair not classified elsewhere had the lowest real benefit. If Thailand were to use an indicator of environmental harm, especially within the services sector, it could help to formulate efficient policies and strategies for the country in 3 areas of development (social, economic, and environmental development).
\end{abstract}

KEY WORDS: Services sector $\cdot$ Forward linkage $\cdot$ Real benefit $\cdot$ Environment cost $\cdot$ Carrying capacity $\cdot$ Sustainable development

\section{INTRODUCTION}

Among the most important factors in the development of a country are environmental and natural resources (TDRI 2007, ADB 2014). However, social and economic changes within Thailand have caused a deterioration in environmental and natural resources, i.e. loss of forests, wild animals, mangrove forests (TDRI 2007), and water resources (Bodini 2012), as well as increased waste. Furthermore, natural resources are limited, whereas consumption of natural resources is unlimited (Chen et al. 2010), and this can cause environmental and natural resources to decrease immediately (NESDB 2015) and continuously. The Thai government has foreseen this, leading ministers to announce a sustainable development policy with the aim to increase economic growth together with social and environmental development (TDRI 2007). Addressing environmental and natural resource degradation should be the first priority for

*Corresponding author: pruethsan@gmail.com
Thai society in making a development plan (ADB 2014), which must correspond with the economic and social development strategy of the Ministry of Natural Resources and Environment.

Marull et al. (2010) stated that the principal policy of a country must address environmental problems and impacts after the policy has been implemented. Policy prior to this research, however, did not focus sufficiently on environmental issues, leading to ineffective management of environmental problems (Simpson \& Bradford 1996). The index of sustainable economic welfare (ISEW) is an indicator used to direct sustainable development of a country and for economic welfare measurement (Bodini 2012). The ISEW not only considers consumption value, but also incorporates unsustainable environmental costs and social costs (Liang \& Zhang 2011). Comparing ISEW per capita with gross domestic product (GDP) per capita in Thailand for the period 1977 to 2003 shows that ISEW per capita before 1977 was consistent with

() The authors 2016. Open Access under Creative Commons by Attribution Licence. Use, distribution and reproduction are unrestricted. Authors and original publication must be credited. 
GDP per capita, during which time the growth rate was positive (ADB 2014). However, after 2003, the 2 indices diverged and economic growth rate decreased (NESDB 2015). ISEW per capita decreased by $6.70 \%$, whereas GDP per capita fell by only $0.89 \%$.

Businesses and consumers are the major players in an economic system (Li et al. 2012). Consumers want to gain high utilization under limited budgets, whereas businesses aim to maximize their profit and reduce expenditures (Hugo \& Pistikopoulos 2005). Neither party pays attention to environmental cost, causing over-consumption and over-production (ADB 2014). However, sustainable development for the country should develop in 3 dimensions collectively; namely economic, social, and environmental. Previously, Thailand gave priority to developing only economic growth. Moreover, the National Economic and Social Development Board (NESDB) stated that firms did not consider the cost of (1) natural resources materials, (2) energy and transportation, (3) fertilizer and pesticides, and (4) sanitary and similar services, which represent environmental costs (NESDB 2015). As a result, Thailand did not achieve sustainable development because economic growth was accompanied by growth in environmental costs.

The services sector represents the main occupation for many people in Thailand, and it consistently generates high income to the country (TDRI 2007). At the same time, the Asian Development Bank (ADB 2014) found that the services sector has been using environmental and natural resources at an increasingly high rate compared with other sectors of the economy. Thus, the government must give increased attention to managing environmental problems caused by the services sector because this production sector influences the economic growth of the country. Moreover, the government should prioritize its efforts by considering the income and cost of economic sectors in proportion to their scale. Finally, they should prepare solutions to deal with problems and trends that might occur in the future.

Accordingly, the formulation of policy and strategies to develop the country must address the real benefit and environmental costs in the 3 dimensions mentioned above (ADB 2014). In addition, the prioritizing of environmental problems should be clearly defined. All of these factors could be included in an index to indicate environmental problems and lead to sustainable solutions in the future, which is the main emphasis of this research.

The objective of this study is to propose an indicator to evaluate environmental impacts of the services sector in Thailand, leading to more sustainable consumption and production in this sector of the economy.

\section{MATERIALS AND METHODS}

\section{Scope of study}

The environmental and natural resource costs are calculated for each service sector using data from Thailand's input-output table. This table expresses the country's total output as a production lineage in which the goods and services produced by one industry are used as input into the production of the goods and services of another industry. The value of the output of each industry can be expressed as the sum of the values of all the inputs to that industry down through the lineage. The calculation uses input data categorized as natural resources materials, energy and transportation, fertilizer and pesticides, and sanitary and similar services. The effects from consumption of the services are not included in environmental cost.

The main calculations in this study use data from the input-output table of Thailand for 2015, which are the most current data. The precision of the calculations is limited by the economic and social descriptions used to create the input-output table.

\section{Conceptual framework}

The conceptual framework (Fig. 1) for evaluating service sectors in terms of their environmental costs is based on the aims and concepts of sustainable development. Three supporting concepts are welfare economics of A. C. Pigou, natural resource economics, and ecology economics (ADB 2014).

\section{Modeling}

The model used in this study is related to the inputoutput table, in which the relationships of the data are categorized by rows and columns as in Table 1 (Leontief 1986).

Rows present the output distribution of product sector $i$ for $n$ product sectors and the gross product of product sector $i$ can be defined, for $1 \leq i \leq n$, by

$$
X_{i}=\sum_{i=1}^{n} X_{i j}+F_{i}
$$




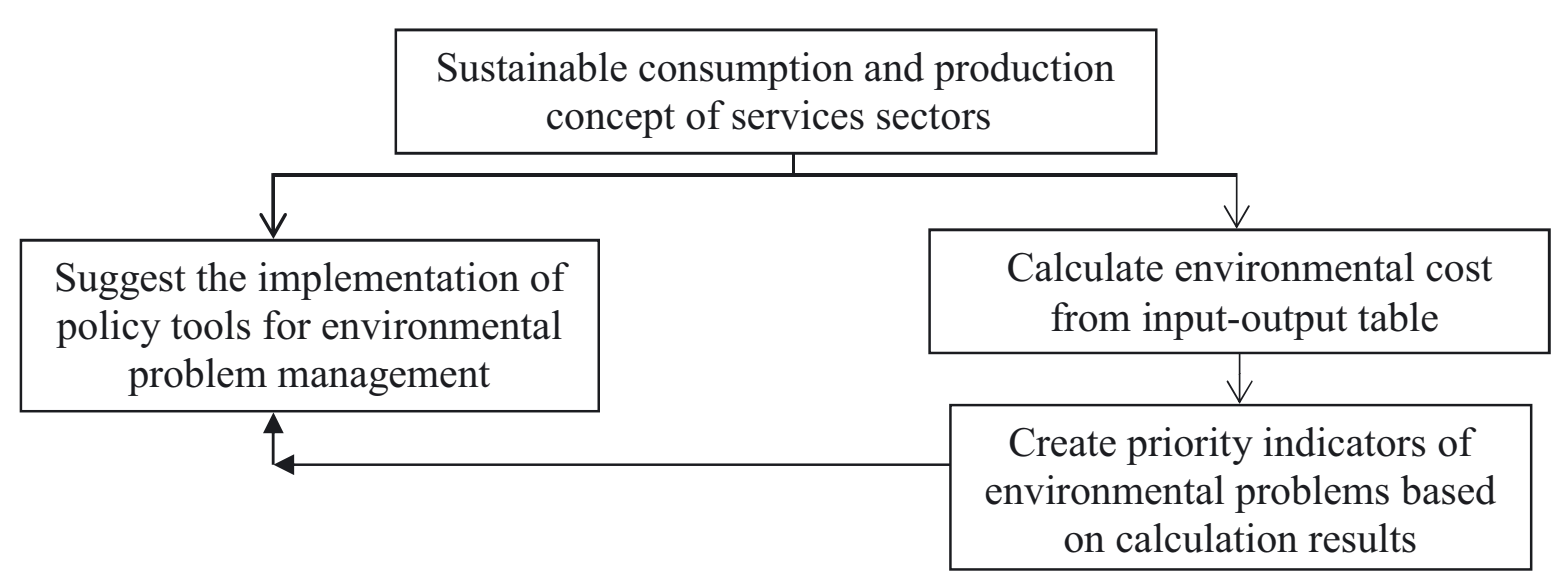

Fig. 1. Conceptual framework

where $X_{i}$ refers to gross product of product sector $i_{\text {, }}$ $X_{i j}$ refers to the product distribution of product sector $i$ of goods and services production for product sector $j$, and $F_{i}$ refers to the final demand of product sector $i$.

Columns show the structure expenses or cost of goods production for product sector $j\left(X_{j}\right)$ that can be defined, for $1 \leq j \leq n$, by

$$
X_{i}=\sum_{j=1}^{n} X_{i j}+V_{j}
$$

where $V_{j}$ refers to the value added of product sector $j$, only if input value is directly proportional to the output value. Then $X_{i j}$ can be defined by the relationship of output $(X)$, input coefficient $(A)$, and final demand $(F)$ of the production structure for the economic system that can be defined by

$$
\begin{gathered}
X=A X+F \\
X=[I-A]^{-1} F
\end{gathered}
$$

$[I-A]^{-1}$ is the Leontief inverse matrix, which is important for economic system analysis using an input-output table. The inverse matrix acts as a direct and indirect input coefficient of the production supply chain that can be used for supply chain length and intensity calculation. The environmental cost when studying each product or service's production can use the multiplication of the environmental cost coefficient and the inverse matrix. Finally, the result represents the total effect of the supply chain that accumulated the environmental cost of each product or service's production. The result also shows the intensity of backward environmental effects of direct and indirect input and output. Furthermore, the result presents names, sectors, and intensity of environmental cost, which are useful for formulating an efficient policy and environmental problem-solving.

Relationships in the input-output table bring about a small change in the final demand of each product sector $(\Delta F)$, which is called a multiplier for final goods and services. Eq. (5) presents the multiplier for the final goods and services calculation.

$$
\Delta X=[I-A]^{-1} \Delta F
$$

Table 1. Matrix used to create the input-output table of economic sectors $\mathrm{X}_{i}=$ value of the output of sector $i(i=1 \ldots \mathrm{n}) ; \mathrm{X}_{i j}=\mathrm{sales}$ by sector $i$ to sector $j$, or the value of inputs from sector $i$ used to produce the output of sector $j(i=1 \ldots n ; j=1 \ldots \mathrm{n})$. It represents the amount of the $i$ th sector output used by the $j$ th sector to produce its output; $\mathrm{L}_{j}=$ wages in sector $j(j=1 \ldots \mathrm{n})$. It represents

\begin{tabular}{|c|c|c|c|c|c|c|c|c|}
\hline \multirow[b]{2}{*}{ Producing sector } & \multirow{2}{*}{ Using sector } & \multicolumn{2}{|c|}{ Processing sectors } & \multirow{2}{*}{\multicolumn{3}{|c|}{ Final demand }} & - & \multirow{2}{*}{$\begin{array}{c}\text { Total } \\
\text { outputs (X) }\end{array}$} \\
\hline & & 1 & 2 & & & & & \\
\hline \multirow[t]{2}{*}{ Processing sectors } & 1 & $x_{11}$ & $x_{12}$ & $C_{1}$ & $i_{1}$ & $g_{1}$ & $e_{1}$ & $x_{1}$ \\
\hline & 2 & $x_{21}$ & $x_{22}$ & $C_{2}$ & $i_{2}$ & $g_{2}$ & $e_{2}$ & $x_{2}$ \\
\hline \multirow[t]{3}{*}{ Payments sectors } & Value added & $l_{1}$ & $l_{2}$ & $l_{C}$ & $l_{1}$ & $l_{g}$ & $l_{e}$ & $\mathrm{~L}$ \\
\hline & & $n_{1}$ & $n_{2}$ & $n_{c}$ & $n_{1}$ & $n_{g}$ & $n_{e}$ & $\mathrm{~N}$ \\
\hline & Imports & $m_{1}$ & $m_{2}$ & $m_{C}$ & $m_{1}$ & $m_{g}$ & $m_{e}$ & M \\
\hline Total outlays (X') & & $x_{1}$ & $x_{2}$ & $\mathrm{C}$ & $\mathrm{I}$ & $\mathrm{G}$ & $\mathrm{E}$ & $\mathrm{X}$ \\
\hline
\end{tabular}
the use of labor in the production of the $i$ th product; $\mathrm{N}_{j}=$ interest and profits in sector $j_{i} \mathrm{M}_{j}=$ imports of sector $j_{i} \mathrm{C}_{j}=$ personal consumption expenditures for the output of sector $i_{i} \mathrm{I}_{j}=$ investment expenditures for the output of sector $i_{i} \mathrm{G}_{j}=$ government purchases of the output of sector $i_{i} \mathrm{E}_{j}=$ exports of the output of sector $i$ 
If final demand $(\Delta F)$ changes, environmental cost will increase $(\Delta E)$. Eq. (6) represents the increasing of environmental cost:

$$
\Delta E=R[I-A]^{-1} \Delta F
$$

where $R$ is the coefficient of inverse matrix.

\section{RESULTS AND DISCUSSION}

Table 2 lists the top 10 service sectors in terms of forward linkage (distribution chain connecting a producer or supplier with customers), real benefit, and each category of environmental cost. Real benefit is the revenue for a sector, minus the environmental costs. The average real benefit was 0.709 . If the real benefit for a given industry is lower than the average, it can be considered to represent a loss, while values higher than the average represent profit. The average value for environmental cost in terms of natural resources materials was 0.0276 ; for energy and transportation, 0.119; for fertilizer and pesticides, 0.006; and for sanitary and similar services, 0.001. If the cost for a particular industry is lower than the average, there is further capacity for production. Environmental cost values that are higher than the average signify that there is no further capacity for production.

Highlights from the findings include the following:

(1) The service sector with the highest environmental cost in terms of natural resources materials was hotels and places of lodging. The cost index was above average, signifying that this sector does not have capacity for further production. In contrast, the lowest natural resources materials environmental cost was for life insurance services.

(2) Hotels and places of lodging also had the highest environmental cost in terms of energy and transportation. The lowest energy and transportation environmental cost was for other insurance services.

(3) The highest environmental cost in terms of fertilizer and pesticides was found in personal services, while the lowest was in real estate.

(4) Movie theaters were found to have the highest environmental cost for sanitary and similar services. In contrast, other community services had the lowest environmental cost for this category.

(5) The highest real benefit in the services sector was for real estate, while the lowest real benefit was for repair not classified elsewhere. The lowest level of real benefit could signify loss in profit.

(6) The highest forward linkage in the services sector was for movie theaters, while the lowest forward linkage was for real estate.
This research is a pilot study of environmental costs of production of services in the economic system of Thailand, using the input-output database to account for differences among sectors. Environmental cost contributes damage to the environment and is affected by the behavior and decisions of producers, consumers, and the government (ADB 2014). The environmental cost cannot be estimated from activities occurring in the market alone. Instead, the estimation of the environmental cost of each production sector in Thailand needs to incorporate environmental cost, which reflects environmental cost. The information can be used to compare the environmental cost of production sectors, and could help to create an environmental problem management indicator (TDRI 2007). The environmental cost modeled in this study relies on 4 groups of economic data, including costs of (1) natural resources materials, (2) energy and transportation, (3) fertilizer and pesticides, and (4) sanitary and similar services.

This research calculates the forward linkage of goods and services production by the addition of 1 unit of GDP. The result from this calculation portrays the economic connectivity of each product sector resulting from economic growth and economic net income (ADB 2014). The purpose of environmental problem management is to reduce negative impacts from the environmental costs to the economic system. Production sectors have been systematically studied and significant environmental costs of production have been identified already.

The result from this calculation portrays the economic connectivity of each product sector resulting from economic growth and economic net income (ADB 2014). The purpose of environmental problem management is to reduce negative impacts from the environmental costs to the economic system. Production sectors have been systematically studied and significant environmental costs of production have been identified already.

Thailand and other Association of Southeast Asian Nations (ASEAN) countries have not created an environmental problem indicator using real benefit, environmental cost, and environmental problems, and this has led them to formulate ineffective policies and plans for their countries (ADB 2014). More developed countries, like Japan and European countries, give importance to environmental stewardship, and their efforts can be reflected in higher green GDP. This methodology would help Thailand formulate efficient policy and forecast future conditions more accurately, allowing the nation to deal with crises arising from environmental problems (NESDB 2015). 


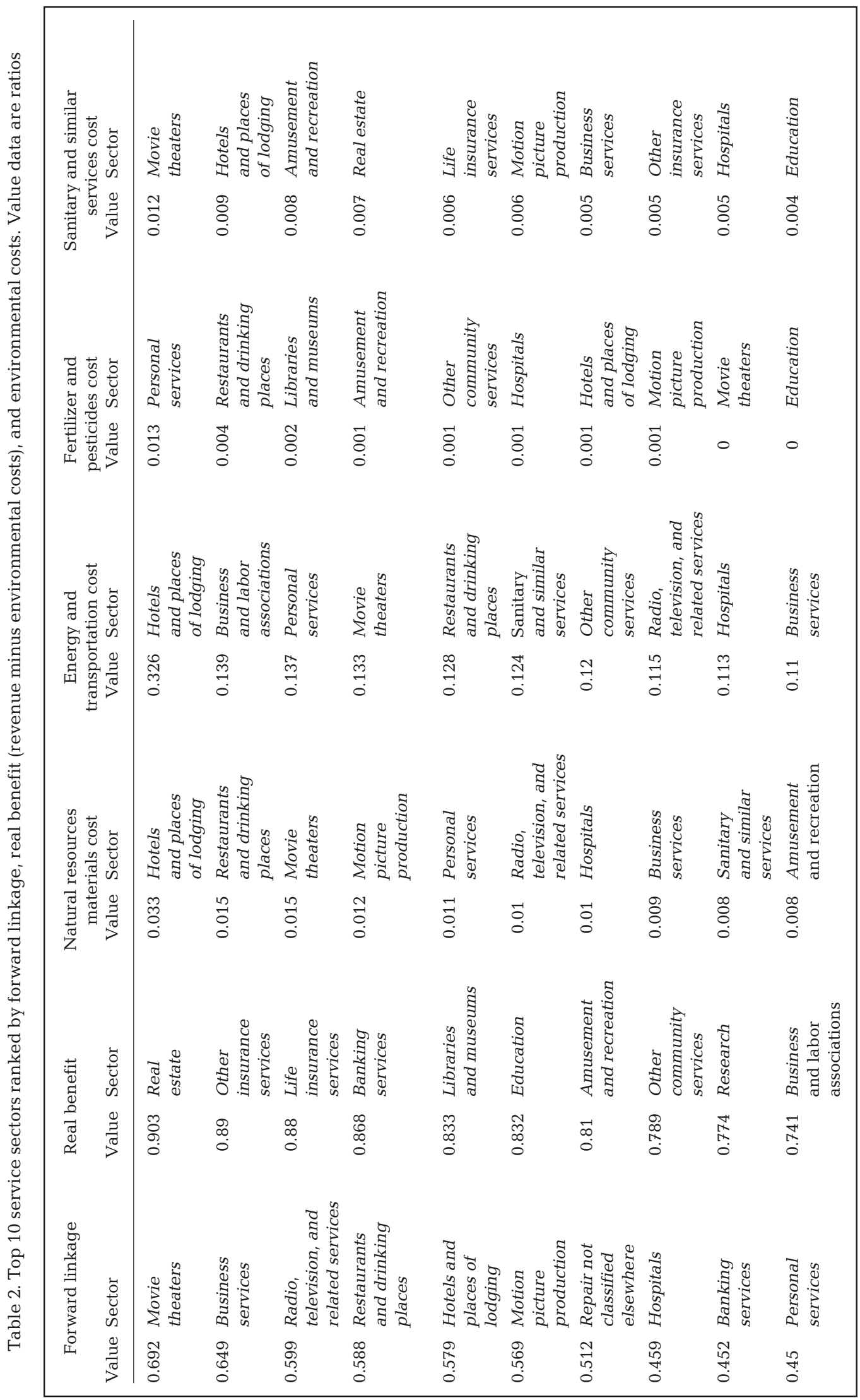


The results of this examination of environmental costs by each sector is consistent with the research of Bodini (2012), and Bailey et al. (2004). The results of the real benefit analysis is also consistent with the research of Simpson \& Bradford (1996), who used the average value of total sectors to create the environmental costs index.

Decisions on the management of environmental problems under a limitation of resources in administration under the sustainable production concept need to use the correct natural resources and environment capital databases. These decisions can be implemented with appropriate planning for environmental management for the pretext of society to lead to sustainable development.

The sector groups with the highest natural resources materials costs according to this study are hotels and places of lodging, restaurants and drinking places, and movie theaters. In these sector groups, the state should promote economic and effective consumption, so that use is reduced, and recycling and reuse is promoted, by utilizing new economic tools such as specifying the right to use resources (property rights), financial instruments, and fiscal instruments (Xu 2010, NESDB 2015).

The sector groups which showed the highest costs of fertilizer and pesticides were personal services, restaurants and drinking places, and libraries and museums. Tools and controls to check that the use of fertilizers and pesticides does not exceed levels that are dangerous for humans and ecology, as well as economic incentive instruments, such as fiscal instruments of differing taxes for dangerous and nondangerous products, could be introduced (Ness et al. 2007).

Sector groups with the highest sanitary and similar services costs are movie theaters, hotels and places of lodging, amusement and recreation, real estate, life insurance services, motion picture production, business services, other insurance services, hospitals, and education. Fiscal instruments such as pollution tax should be considered here. In addition, local administrations could improve regulation by using differing charges and fines for different activities to reflect the costs of waste disposal (ADB 2014).

The indicator showed that the top 10 production sectors with the highest environmental issues were (1) movie theaters, (2) business services, (3) radio, television, and related services, (4) restaurants and drinking places, (5) hotels and places of lodging, (6) motion picture production, (7) repair not classified elsewhere, (8) hospitals, (9) banking services, and (10) personal services. Fiscal incentive instruments should be considered here, such as the reduction of corporate income tax for energy conservation based on actual savings, which has been shown to give more benefit than reduction of tax from money invested for conservation of energy, although both methods are tools that have been used for conservation of energy (TDRI 2007, NESDB 2015).

\section{CONCLUSIONS}

Thailand has adopted policies predominantly focused on economic growth and prosperity from very early in its history. Former governments emphasized improving GDP without taking into consideration the consequences of such policies on Thailand's environment (TDRI 2007). This mismanagement has led to subsequent instability and crises in the country. The rapid economic development of Thailand has come at the cost of environmental degradation and the depletion of its natural resources. This calls for proactive measures that address the complex nature of the issues and the creation of environmental indicators that can be effectively used to set state policies and strategies in the future.

Indicators of environmental issues are essential tools to help direct policies and strategies of Thailand's government. The real benefit from each production sector can not only be judged by the size of the output, but must also reflect the level of environmental cost created by the production. Consequently, it is necessary to calculate an environmental indicator in order to prioritize the most urgent environmental issues in order to achieve more sustainable development. This study aimed to develop indicators to help guide decisions to achieve more sustainable development. The indicators were divided into 5 categories; namely natural resources materials costs, energy and transportation costs, fertilizer and pesticides costs, sanitary and similar services costs, and forward linkages (NESDB 2015). To calculate the indicators, average cost values for each production sector were used. If a sector had environmental costs that were higher or equal to the sector average, the sector was considered inefficient in its production of services, and should take measures to lower environmental costs. Researchers also developed forward linkage values in order to identify sectors causing environmental harm that needs to be addressed immediately. The sectors with highest forward linkage should have priority, followed by others, according to their forward linkage value (ADB 2014). Thailand's economic development plan must integrate 
environmental indicators such as those from this research to create efficient strategies and policies for sustainable development. In the past, Thailand did not incorporate environmental indicators in policy planning, and as a result, the environment and natural resources have been mismanaged to beyond a sustainable capacity. The indicators in this research will greatly improve state policies addressing environmental sustainability.

Acknowledgements. This work was performed with the approval of the Institute for Population and Social Research, Mahidol University and the Office of the National Economic and Social Development Board.

\section{LITERATURE CITED}

ADB (Asian Development Bank) (2014) Environment, climate change, and disaster risk management. $\mathrm{ADB}$, Manila

Bailey R, Allen JK, Bras B (2004) Applying ecological inputoutput flow analysis to material flows in industrial systems. I. Tracing flows. J Ind Ecol 8:45-68

Bodini A (2012) Building a systemic environmental monitoring and indicators for sustainability: What has the ecological network approach to offer? Ecol Indic 15:140-148

Chen ZM, Chen GQ, Zhou JB, Jiang MM, Chen B (2010) Ecological input-output modeling for embodied resources and emissions in Chinese economy 2005. Com-

Editorial responsibility: Darryl Macer,

Scottsdale, Arizona, USA mun Nonlinear Sci Numer Simul 15:1942-1965

Hugo E, Pistikopoulos EN (2005) Environmentally conscious long-range planning and design of supply chain networks. J Clean Prod 13:1471-1491

Leontief WW (1986) Input-output economics, 2nd edn. Oxford University Press, New York, NY

Li SS, Zhang Y, Yang ZF, Liu H, Zhang JY (2012) Ecological relationship analysis of the urban metabolic system of Beijing China. Environ Pollut 170:169-176

> Liang S, Zhang T (2011) Urban metabolism in China: achieving dematerialization and decarbonization in Suzhou. J Ind Ecol 15:420-434

Marull J, Pino J, Tello E, Cordobilla MJ (2010) Social metabolism, landscape change and land-use planning in the Barcelona metropolitan region. Land Use Policy 27: 497-510

NESDB (Office of the National Economic and Social Development Board) (2015) National income of Thailand. NESDB, Bangkok

> Ness B, Urbel-Piirsalu E, Anderberg S, Olsson L (2007) Categorizing tools for sustainability assessment. Ecol Econ 60:498-508

Simpson DR, Bradford RL (1996) Taxing variable cost: environmental regulation as industrial policy. J Environ Econ Manage 30:282-300

TDRI (Thailand Development Research Institute) (2007) Prioritizing environmental problems with environmental costs. Final report prepared for the Thailand Health Fund, Bangkok

$\mathrm{Xu}$ M (2010) Development of the physical input monetary output model for understanding material flows within ecological-economic systems. J Resour Ecol 1: 123-134

Submitted: September 9, 2015; Accepted: March 29, 2016

Proofs received from author(s): June 4, 2016 